\title{
Extration, identification and stability ananlysis of anthocyanins from organic Guizhou blueberries in China
}

\author{
Mingyue YIN ${ }^{1 *}$ (i), Jiao XIE ${ }^{1}$, Chun XIE ${ }^{1}$, Mao LUO ${ }^{1}$, Xin YANG ${ }^{1}$
}

\begin{abstract}
Guizhou Majiang organic blueberries from China are a prevalent fruit in the health industry and have high anthocyanin contents. This study used the ethanol extraction method, ultrasonic-assisted extraction, AB 8 macroporous resin adsorption purification, and the addition of $3 \%$ citric acid to extract anthocyanins, and through single-factor tests and orthogonal tests, the optimum extraction conditions of anthocyanins from blueberries was determined. The optimal extraction conditions were as follows: the extraction temperature was $40^{\circ} \mathrm{C}$, the ethanol volume fraction was $80 \%$, the solid-liquid ratio was $1: 10$, the ultrasonic extraction time was $60 \mathrm{~min}$, and the extraction amount was $2.56 \mathrm{mg} / \mathrm{g}$. Anthocyanins were identified by HPLC, and the effects of storage conditions on their contents were investigated. $\mathrm{K}^{+}, \mathrm{Cu}^{2+}$, and $\mathrm{Fe}^{2+}$ had little influence on anthocyanin contents, while hydrogen peroxide had a highly destructive effect. With increasing illumination time, the retention rate of anthocyanins decreased gradually; the higher the temperature was, the stronger the damaging effect on anthocyanin contents, and the appropriate storage temperature was determined to be $-4{ }^{\circ} \mathrm{C}$ or below. The absorbance was the highest when $\mathrm{pH}=2$. Taken together, the results of our study revealed the optimal extraction process and appropriate preservation conditions of anthocyanins from organic Guizhou blueberries.
\end{abstract}

Keywords: blueberry anthocyanins; extraction; orthogonal test; HPLC; stability analysis.

Practical Application: Anthocyanins have strong antioxidant properties, and they are widely used in medicine and health care products. In this study, the optimal extraction conditions to achieve the highest extraction yield of anthocyanins from organic Guizhou blueberries were obtained. The appropriate conditions for the preservation of anthocyanins were also investigated. This study provides a data reference for the extraction and application of anthocyanins in blueberries.

\section{Introduction}

Blueberries are the health fruit of the 21st century, and they are gaining popularity as consumers demand healthier, more nutritious food products. Organic Majiang blueberries are a specialty of Guizhou Miao and Dong autonomous county and are one of China's national geographical indication products. In the first year of the 13th Five-year Plan, Guizhou Province proposed the "Great poverty alleviation", "Big Data", and "Great Health" as three big development strategies; the "great health" strategy covers pharmaceutical plant cultivation, drug development, health food, health tourism, health services, and other fields. Blueberries were rated as one of the five human health foods by the Food and Agriculture Organization of the United Nations, and Majiang County in Guizhou Province cultivate blueberries with advantageous geographical conditions because it is located in a humid subtropical monsoon climate zone with no cold winter sand hot summers, abundant rainfall, and an annual average temperature of $14 \sim 16^{\circ} \mathrm{C}$, so it is very beneficial to blueberry cultivation. Blueberries contain rich nutrients; in addition to protein, fat, carbohydrates, vitamin $\mathrm{A}$, vitamin $\mathrm{C}$, vitamin $\mathrm{E}$, superoxide dismutase (SOD), $\mathrm{Ca}, \mathrm{P}, \mathrm{Mg}$, $\mathrm{Zn}, \mathrm{Fe}, \mathrm{Cu}$, etc., polyphenols, anthocyanins and phenolic acids are the main components of blueberry polyphenols and have good antioxidant activity and scavenging effects on reactive oxygen species in cells (Thomasset et al., 2009; Urias-Lugo et al., 2015).
Blueberries have high anthocyanin contents and contain several anthocyanins (Hu et al., 2006; Mikulic-Petkovsek et al., 2012), such as delphinium, cornflower pigment, petunia pigment, peony anthocyanin, and mallow pigment (Chorfa etal., 2016). However, anthocyanins are particularly unstable in nature and combine with different monosaccharides, disaccharides, trisaccharides and other compounds to form anthocyanin compounds in plants. Therefore, anthocyanins in nature exist in the form of anthocyanin complexes.

Anthocyanins have a variety of biological functions, including antioxidant, antitumor, vision-protective, cardiovascular diseasepreventive, anti-inflammatory, antiaging, immune-enhancing, estrogen-like effects (Diaconeasa et al., 2015), control metabolic syndrome and obesity (Yildiz et al.,2020). Therefore, it is particularly important and meaningful to explore a simple and safe method to extract anthocyanins from blueberries. At the same time, due to the instability of anthocyanins, it is necessary to explore their appropriate storage conditions. Ethanolacidified with $0.01 \% \mathrm{HCl}$ was an effective extractant of anthocyanins, and ultrasound treatment may further improve the extraction of anthocyanins (Silva et al., 2017).

Therefore, in this work, the optimum extraction conditions of anthocyanins from Majiang blueberries were studied by orthogonal testing with the aid of ultrasonication and citric acid. 
The anthocyanins were identified by HPLC, and the stability of anthocyanins was analyzed. The aim of this study was to provide a basis for the extraction, preservation and application of blueberry anthocyanins.

\section{Materials and methods}

\subsection{Materials}

Fresh and organic samples of blueberry fruits of the Canlan variety were harvested in Majiang County in Guizhou (China). Ab-8 macroporous resin were purchased from Solarbio (USA). Petroleum ether was purchased from Nanjing Zhongchun Biotechnology Co., Ltd (China). A rotary evaporator was purchased from Shanghai Yarong Biochemical Instrument Factory (China). A vacuum freeze dryer was purchased from Shanghai Bilang Instrument Manufacturing Co., Ltd (China). An ultrasonic cleaner was purchased from Kunshan Shumei Ultrasonic Instrument Co., Ltd (China). A high-performance liquid chromatography (HPLC)instrument (1100 series) was purchased from Agilent (USA). Cyanidin 3-O-glucoside (CGE) was purchased from PhytoLab (GERMANY).

\subsection{Extraction and purification of blueberry anthocyanins}

Blueberry anthocyanins were extracted by using ethanol extraction, with the use $\mathrm{Ab} 8$ macroporous resin for purification. Specifically, $200 \mathrm{~g}$ of blueberries was accurately weighed, combined with 3\% citric acid (for extraction assistance and the prevention of anthocyanin oxidation) and ground into homogenate, according to a certain proportion of material to liquid. Then, a certain volume fraction of acid (hydrochloric acid content of $0.2 \%$ ) was added, the mixture was subjected to roomtemperature oscillation for $30 \mathrm{~min}$, and then ultrasonication at a power of $100 \mathrm{~W}$ was applied (this power can be achieved with an ordinary ultrasonic cleaning instrument in the laboratory and does not require special equipment, which is convenient for the popularization of this experimental method). Blueberry anthocyanins were extracted by ultrasonication for some time, and then filtration and petroleum ether extraction were implemented prior to $\mathrm{AB} 8$ macroporous resin adsorption. The anthocyanins were eluted with $75 \%$, the eluate was placed in a rotary evaporation apparatus at $45^{\circ} \mathrm{C}$ to evaporate the ethanol, and the anthocyanin concentrate was obtained.

The $\mathrm{AB} 8$ macroporous resin was pretreated by soaking the macroporous resin with distilled water for $24 \mathrm{~h}$ to achieve full swelling. A column was packed with the resin, which was then washed with 2 volumes of $95 \%$ ethanol and subsequently 2 volumes of deionized water to remove all ethanol. The column was then washed with an equal volume of a $4 \%$ hydrochloric acid solution and water until the $\mathrm{pH}$ was neutral.

\subsection{Total anthocyanin content}

The total anthocyanin content was measured by the $\mathrm{pH}$ differential (PD) method. In the determination of the anthocyanin content in blueberries, the PD method and HPLC method showed similar trends (Lee et al., 2016). In $\mathrm{pH}=1.0$ and $\mathrm{pH}=4.5$ buffer conditions, $\lambda$ vismax and
$700 \mathrm{~nm}$ absorbance values were determined by ultraviolet spectrophotometry according to the Fuleki $\mathrm{T}$ formula to calculate the anthocyanin content:

Anthocyanin content $(m g / L)=\frac{A \times M W \times D F \times 1000}{\varepsilon \times 1}$

where A refers to (Absorbance $\lambda_{\text {vismax }}-$ Absorbance $\left.\lambda_{700 \mathrm{~nm}}\right) \mathrm{pH}$ 1.0 - (Absorbance $\lambda_{\text {vismax }}-$ Absorbance $\left.\lambda_{700 \mathrm{~nm}}\right) \mathrm{pH} \mathrm{4.5, \textrm {MW }}$ $(449.2 \mathrm{~g} / \mathrm{mol})$ refers to the molecular weight of cya-3-glc, DF refers to the dilution ratio, and $\varepsilon(26,900)$ refers to the molar absorptivity. According to the method by Giusti \& Wrolstad (2001), $\lambda_{\text {vismax }}=510 \mathrm{~nm}$.

Through unit conversion of Formula 1, the total anthocyanin content (mg cyanidin-3-galactoside equivalent/g fresh weight) was estimated by Formula 2:

Anthocyanin content $(m g / g)=\frac{\text { Formula }(1) \times V}{m}$

where $\mathrm{V}$ refers to the extraction liquid volume and $\mathrm{M}$ refers to the mass of the blueberries.

\subsection{Single-factor test}

According to the above experimental procedure, under the condition of a fixed ultrasonic power of $100 \mathrm{~W}$, the effects of four factors (the solid-liquid ratio, ethanol volume fraction, ultrasonic extraction time and extraction temperature) on anthocyanin extraction were investigated. The specific conditions were set as follows: the ultrasonic extraction temperature was set to $20^{\circ} \mathrm{C}, 30^{\circ} \mathrm{C}, 40^{\circ} \mathrm{C}, 50^{\circ} \mathrm{C}$ and $60^{\circ} \mathrm{C}$; the ultrasonic extraction time was set to $30 \mathrm{~min}, 40 \mathrm{~min}$, $50 \mathrm{~min}, 60 \mathrm{~min}$ and $70 \mathrm{~min}$; the ethanol volume fraction was set to $40 \%, 50 \%, 60 \%, 70 \%$ and $80 \%$; and the solid-liquid ratio set to $1: 4,1: 6,1: 8,1: 10$ and $1: 12$.

\subsection{Orthogonal test}

Based on the results of the single-factor test, the orthogonal test with 4 factors and 3 levels was selected. Four influencing factors, namely, extraction temperature, extraction time, ethanol volume fraction and solid-liquid ratio, were named A, B, C and $\mathrm{D}$, respectively. In combination with single-factor test results, the optimal three levels from each factor were combined, and a four-factor three-level orthogonal experiment was carried out.

\subsection{Measurement of total anthocyanin contents by HPLC with CGE}

A high-performance liquid chromatography (HPLC) system (Agilent Model 1100, USA) equipped with a C18 column ( $4.6 \mathrm{~mm} \times 250 \mathrm{~mm}, 5.0 \mu \mathrm{m}$, Agilent, USA) was used. The method was performed as previously described (Wang et al., 2000), with appropriate adjustments. Gradient elution of anthocyanin extracts was conducted with an $8.5 \%$ aqueous methanol solution as eluent $\mathrm{A}$, and 22.5:6.5:41.5 acetonitrile : 
methanol: water. The flow rate and column temperature were maintained at $0.8 \mathrm{~mL} / \mathrm{min}$ and $35^{\circ} \mathrm{C}$, respectively. The wavelength was set at $510 \mathrm{~nm}$. Cyanidin 3-O-glucoside (CGE) was used as the standard.

\subsection{Stability test}

Metal ions on the stability of anthocyanins

Solutions of different concentrations of $\mathrm{K}^{+}, \mathrm{Cu}^{2+}$, and $\mathrm{Fe}^{2+}$ were used to dilute blueberry anthocyanin extracts to concentrations of $10 \mathrm{mmol} / \mathrm{L}$ and $20 \mathrm{mmol} / \mathrm{L}$, respectively, placed in the dark, and the absorbance was measured at $510 \mathrm{~nm}$ every $24 \mathrm{~h}$ for 8 days.

\section{Antioxidant effect on the stability of anthocyanins}

In the $\mathrm{pH}=3$ blueberry anthocyanin extracts, different volumes of a $\mathrm{H}_{2} \mathrm{O}_{2}$ solution were added to achieve concentrations were $0.1 \mathrm{~mL} / 100 \mathrm{~mL}, 0.5 \mathrm{~mL} / 100 \mathrm{~mL}$ and $1.0 \mathrm{~mL} / 100 \mathrm{~mL}$ and were placed in the dark. The absorbance was measured at $510 \mathrm{~nm}$ every $24 \mathrm{~h}$ for 8 days.

\section{Effect of light on the stability of anthocyanins}

Ten milliliters of blueberry anthocyanin extract was placed in transparent glass bottles with a cap, exposed to indoor lamplight illumination, sunlight $\left(18 \sim 28^{\circ} \mathrm{C}\right)$ and ultraviolet light, and the absorbance was measured every $2 \mathrm{~h}$ for $8 \mathrm{~h}$.

\section{Effect of temperature on the stability of anthocyanins}

Five $30 \mathrm{~mL}$ brown bottles with caps, and $10 \mathrm{~mL}$ of blueberry anthocyanin extracts were added to each bottle at $4{ }^{\circ} \mathrm{C}, 20^{\circ} \mathrm{C}$, $40^{\circ} \mathrm{C}, 60^{\circ} \mathrm{C}$ and $80^{\circ} \mathrm{C}$ thermostat water baths, and the absorbance was measured every $2 \mathrm{~h}$ for $8 \mathrm{~h}$.

\section{Effect of $\mathrm{pH}$ on the stability of anthocyanins}

Eight $10 \mathrm{~mL}$ aliquots of blueberry anthocyanin extracts were taken, and the $\mathrm{pH}$ value was adjusted to $1,2,3,4,5,6$, 7 , and 8 by disodium hydrogen phosphate and citric acid. The absorbance was measured at $510 \mathrm{~nm}$ every hour to calculate the retention rate of anthocyanins.

The retention rate was calculated by the measured absorbance value, and the Formula 3 is as follows.

$$
\text { Retention rate }(\%)=\frac{\text { Abosrbance after treatment }}{\text { Absorbance before treatment }} \times 100 \%
$$

\subsection{Statistical analysis}

The data are expressed as the means \pm standard deviations. SPSS software (version 20.0, SPSS Inc., USA) was used to analyze the significance of differences. Origin (version 9.0.0, Origin Lab, USA) was employed for statistical analysis and graphing. Orthogonal tests and analysis of variance were used. Statistical significance was taken at the $\mathrm{p}<0.05$ level.

\section{Results}

\subsection{Single-factor test results}

\section{Effects of extraction temperature}

Five portions of $100 \mathrm{~g}$ of blueberry pulp were accurately weighed. According to the solid-liquid ratio of 1:6, the ethanol volume fraction was $60 \%$, and the ultrasonic power was $100 \mathrm{~W}$. Ultrasonication was performed at temperatures of $20^{\circ} \mathrm{C}, 30^{\circ} \mathrm{C}$, $40^{\circ} \mathrm{C}, 50^{\circ} \mathrm{C}$, and $60^{\circ} \mathrm{C}$ for $60 \mathrm{~min}$. After centrifugation, the supernatant was collected, and the absorbance values were measured at wavelengths of $510 \mathrm{~nm}$ and $700 \mathrm{~nm}$.

As shown in Figure 1A, with other parameters being equal, the extraction amount of blueberry anthocyanins reached the highest when the extraction temperature reached $40^{\circ} \mathrm{C}$ and then gradually decreased with the further increase in temperature. The reason may be that the anthocyanins were not completely dissolved when the temperature was low, and it can be completely dissolved when it reached approximately $40 \sim 50{ }^{\circ} \mathrm{C}$. However, because anthocyanins are sensitive to heat, a further increase in temperature leads to anthocyanin decomposition. Therefore, $30 \sim 50{ }^{\circ} \mathrm{C}$ was selected as the factor level of the orthogonal test.

\section{Effects of extraction time}

Five portions of $100 \mathrm{~g}$ of blueberry pulp were accurately weighed. According to the solid-liquid ratio of 1:6, the ethanol volume fraction was $60 \%$, the ultrasonic power was $100 \mathrm{~W}$, and the temperature was $40^{\circ} \mathrm{C}$. Ultrasonication was performed at 30 $\mathrm{min}, 40 \mathrm{~min}$, $50 \mathrm{~min}, 60 \mathrm{~min}$, and $70 \mathrm{~min}$. After centrifugation, the supernatant was collected, and the absorbance values were measured at wavelengths of $510 \mathrm{~nm}$ and $700 \mathrm{~nm}$.

As shown in Figure 1B,with the other parameters held constant, the extraction amount of anthocyanins was the highest when the extraction time was 50 60 min, and the extraction amount decreased slightly as time increased, which indicated that the anthocyanins were completely extracted. Therefore, 50 70 min was selected as the factor level of the orthogonal test.

\section{Effects of ethanol volume fraction}

Five portions of $100 \mathrm{~g}$ of blueberry pulp were accurately weighed. The solid-liquid ratio was 1:6, the ultrasonic power was $100 \mathrm{~W}$, the temperature was $40^{\circ} \mathrm{C}$, the ultrasonic time was $60 \mathrm{~min}$, and the anthocyanins were extracted according to the ethanol volume fractions of $40 \%, 50 \%, 60 \%, 70 \%$ and $80 \%$. After centrifugation, the supernatant was collected, and the absorbance values were measured at wavelengths of $510 \mathrm{~nm}$ and $700 \mathrm{~nm}$.

As shown in Figure 1C, with the other parameters being held constant, the extraction amount of anthocyanins was the highest when the ethanol volume fraction was $70 \%$ and then decreased when the volume fraction increased. This result indicated that a suitable water content was helpful for anthocyanin extraction. Therefore, $60 \% \sim 80 \%$ was selected as the volume fraction factor level of the orthogonal test. 

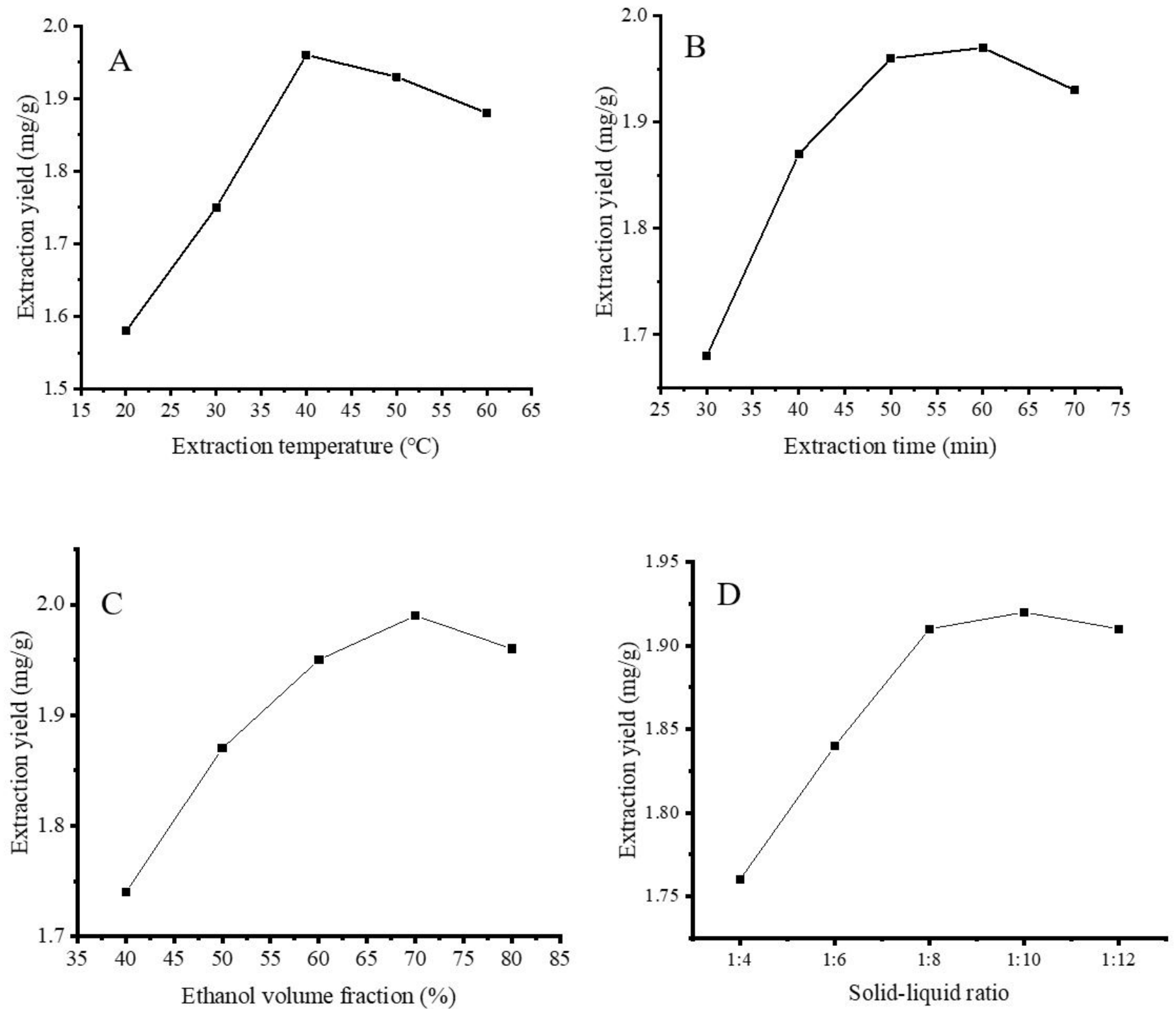

Figure 1. Effects of extraction temperature (A), extraction time (B), ethanol volume fraction (C) and solid-liquid ratio (D) on the extraction yield of anthocyanins.

\section{Effects of solid-liquid ratio}

Five portions of $100 \mathrm{~g}$ of blueberry pulp were accurately weighed. The ethanol volume fraction was $60 \%$, the ultrasonic power was $100 \mathrm{~W}$, the temperature was $40^{\circ} \mathrm{C}$, and the ultrasonic time was $60 \mathrm{~min}$. Anthocyanins were extracted at solid-liquid ratios of 1:4, 1:6, 1:8, 1:10, and 1:12. After centrifugation, the supernatant was collected, and the absorbance values were measured at wavelengths of $510 \mathrm{~nm}$ and $700 \mathrm{~nm}$.

As shown in Figure 1D, with other conditions unchanged, the extraction amount of anthocyanins reached the highest after the solid-liquid ratio reached 1:8 and then tended to plateau. Considering the subsequent concentration and drying of anthocyanin extract, 1:8 1:12 was selected as the factor level of the orthogonal test.

\subsection{Orthogonal test results}

Based on the results of the single-factor experiment, four factors were selected for the three-level orthogonal test: $30{ }^{\circ} \mathrm{C}, 40{ }^{\circ} \mathrm{C}$ and $50{ }^{\circ} \mathrm{C}$ were selected for extraction temperatures (A); 50, 60, and $70 \mathrm{~min}$ were selected for extraction times (B); $60 \%, 70 \%$, and $80 \%$ were selected for ethanol volume fractions $(\mathrm{C})$; and $1: 8,1: 10$, and $1: 12$ were selected for solid-liquid ratios (D). The orthogonal test results are shown in Tables 1 and 2.

The range of factor A was the largest, so the most significant influence on the extraction yield of blueberry anthocyanins was the temperature. The optimum process obtained by the orthogonal test was $\mathrm{A} 2 \mathrm{~B} 2 \mathrm{C} 3 \mathrm{D} 1$, but from the range analysis 
Table 1. Orthogonal test results.

\begin{tabular}{|c|c|c|c|c|c|}
\hline \multirow{2}{*}{$\begin{array}{c}\text { Test } \\
\text { number }\end{array}$} & \multicolumn{4}{|c|}{ Factors } & \multirow{2}{*}{$\begin{array}{c}\text { Anthocyanin } \\
\text { content } \\
(\mathrm{mg} / \mathrm{g})\end{array}$} \\
\hline & $\mathrm{A}\left({ }^{\circ} \mathrm{C}\right)$ & B (min) & $\mathrm{C}(\%)$ & D & \\
\hline 1 & 30 & 50 & 60 & $1: 8$ & 1.63 \\
\hline 2 & 30 & 60 & 70 & $1: 10$ & 1.72 \\
\hline 3 & 30 & 70 & 80 & $1: 12$ & 1.81 \\
\hline 4 & 40 & 50 & 70 & $1: 12$ & 2.31 \\
\hline 5 & 40 & 60 & 80 & $1: 8$ & 2.48 \\
\hline 6 & 40 & 70 & 60 & $1: 10$ & 2.40 \\
\hline 7 & 50 & 50 & 80 & $1: 10$ & 2.13 \\
\hline 8 & 50 & 60 & 60 & $1: 12$ & 1.98 \\
\hline 9 & 50 & 70 & 70 & $1: 8$ & 1.92 \\
\hline K1 & 1.72 & 2.02 & 2.00 & 2.01 & \\
\hline K2 & 2.40 & 2.06 & 1.98 & 2.08 & \\
\hline K3 & 2.01 & 2.04 & 2.14 & 2.03 & \\
\hline $\mathrm{R}$ & 0.68 & 0.04 & 0.16 & 0.07 & \\
\hline $\begin{array}{c}\text { Primary and } \\
\text { secondary } \\
\text { order }\end{array}$ & $\mathrm{A}>\mathrm{C}>\mathrm{D}>\mathrm{B}$ & & & & \\
\hline $\begin{array}{l}\text { Optimal } \\
\text { Level }\end{array}$ & $\mathrm{A} 2 \mathrm{~B} 2 \mathrm{C} 3 \mathrm{D} 1$ & & & & \\
\hline
\end{tabular}

results, it was concluded that the optimal process was A2B2C3D2; this inconsistency required validation of the method.

Anthocyanins were extracted according to the optimum range analysis process $\left(40{ }^{\circ} \mathrm{C}, 60 \mathrm{~min}, 80 \%, 1: 10\right)$, and the extraction amount was $2.56 \mathrm{mg} / \mathrm{g}$, which was higher than that of the orthogonal test under the optimal process (2.48 $\mathrm{mg} / \mathrm{g}$ ). Therefore, the optimal process of A2B2C3D2 was finally chosen.

\subsection{HPLC results}

HPLC has been the most widely used tool for the identification of anthocyanins, in which the individual anthocyanins can be separated by their polarity (Lee et al., 2008). As shown in Figures 2 and 3, using cyanidin 3-O-glucoside (CGE) as the standard, CGE was isolated from blueberry anthocyanin extracts by HPLC.

\subsection{The influence of different storage conditions on blueberry anthocyanin stability}

\section{The influence of metal ions}

As shown in Figure 4, after adding $\mathrm{K}^{+}, \mathrm{Cu}^{2+}$ and $\mathrm{Fe}^{2+}$ to the extracts, with increasing time, the blueberry anthocyanin retention rate gradually decreased but remained above $90 \%$. The influence of $10 \mathrm{mmol} / \mathrm{L} \mathrm{K}^{+}$and $\mathrm{Cu}^{2+}$ on the anthocyanin retention rate was relatively low, and when their concentrations increased to $20 \mathrm{mmol} / \mathrm{L}$, there was no obvious decrease; however, $\mathrm{Fe}^{2+}$ addition at $10 \mathrm{mmol} / \mathrm{L}$ and $20 \mathrm{mmol} / \mathrm{L}$ showed notable and similar decreases in anthocyanin retention.
Table 2. Variance analysis of orthogonal test results.

\begin{tabular}{cccrcc}
\hline $\begin{array}{c}\text { Sources of } \\
\text { variation }\end{array}$ & SS & f & F-ratio & F critical-values & Significance \\
\hline A & 0.691 & 2 & 345.500 & 19.000 & $*$ \\
B & 0.002 & 2 & 1.000 & 19.000 & \\
C & 0.044 & 2 & 22.000 & 19.000 & $*$ \\
D & 0.008 & 2 & 4.000 & 19.000 & \\
\hline
\end{tabular}

Abbreviations and symbols: SS, deviation sum of squares; $\mathrm{f}$, degree of freedom; ${ }^{*}, P<0.05$

The influence of hydrogen peroxide $\left(\mathrm{H}_{2} \mathrm{O}_{2}\right)$

As shown in Figure $5 \mathrm{~A}, \mathrm{H}_{2} \mathrm{O}_{2}$ had a great influence on anthocyanin stability when different volumes of hydrogen peroxide were added and incubated with the extracts for 24 hours, and the anthocyanin retention rates all decreased to approximately $5 \%$.

\section{The influence of light}

As shown in Figure 5B, the influence of natural light and afluorescent lamp on the anthocyanin retention rate was similar; for 4 hours, the anthocyanin retention rate decreased to approximately $88 \%$ and then plateaued. However, after ultraviolet light irradiation for 2 hours, the retention rate fell to $86 \%$ and then plateaued.

\section{The influence of temperature}

As shown in Figure $5 \mathrm{C}$, after storage at $-4{ }^{\circ} \mathrm{C}$, the anthocyanin retention rate after $8 \mathrm{~h}$ changed very little. At $20^{\circ} \mathrm{C}$, the anthocyanin retention rate was above $80 \%$, and then, with increasing temperature and time, the anthocyanin retention rate gradually declined.

\section{The influence of $p H$}

As shown in Figure 5D, the absorbance value of blueberry anthocyanins decreased first and then increased in the $\mathrm{pH}$ range of 2-8. When $\mathrm{pH}=2$, the retention rate reached its maximum, and when $\mathrm{pH}=5$, it reached its minimum.

\section{Discussion}

Scholars have performed some studies on the extraction conditions of anthocyanins from blueberry, but some of the extraction amounts were not specific, or the extraction conditions required large volumes of solvent. In this study, the anthocyanins extraction amount from organic Guizhou blueberries was $2.56 \mathrm{mg} / \mathrm{g}$ by applying simple conditions and easily available instruments. Xu et al. (2016) used cellulose and pectinase as a raw material under the optimal extraction conditions of $37^{\circ} \mathrm{C}, 2: 1(\mathrm{~m} / \mathrm{m}), 75 \%(\mathrm{v} / \mathrm{v})$ citrate ethanol and $6 \mathrm{~h}$. The extraction rate of blueberry anthocyanins reached $25 \%$, and the purity reached $49.6 \%$ after ethyl acetate extraction. In Duan et al.'s (2015) study, a microwave-assisted extraction was used to extract the anthocyanins from Chinese bayberry, the anthocyanin content was $2.95 \pm 0.08 \mathrm{mg} / \mathrm{g}$, the extraction time 
was reduced to $15 \mathrm{~min}$; however the extraction temperature was $80{ }^{\circ} \mathrm{C}$, anthocyanins may be affected. Xue et al. (2018) found that under microwave-assisted extraction conditions, the critical extraction temperature for optimum anthocyanin yield was $50.75 \pm 0.88^{\circ} \mathrm{C}$, and the highest contents of pelargonidin, cyanidin, and delphinidin from blueberries were $1.02 \mu \mathrm{g} / \mathrm{mL}$, $0.66 \mu \mathrm{g} / \mathrm{mL}$, and $0.31 \mu \mathrm{g} / \mathrm{mL}$, respectively. Hutabarat et al. (2019) used the Box-Behnken test to investigate the effect

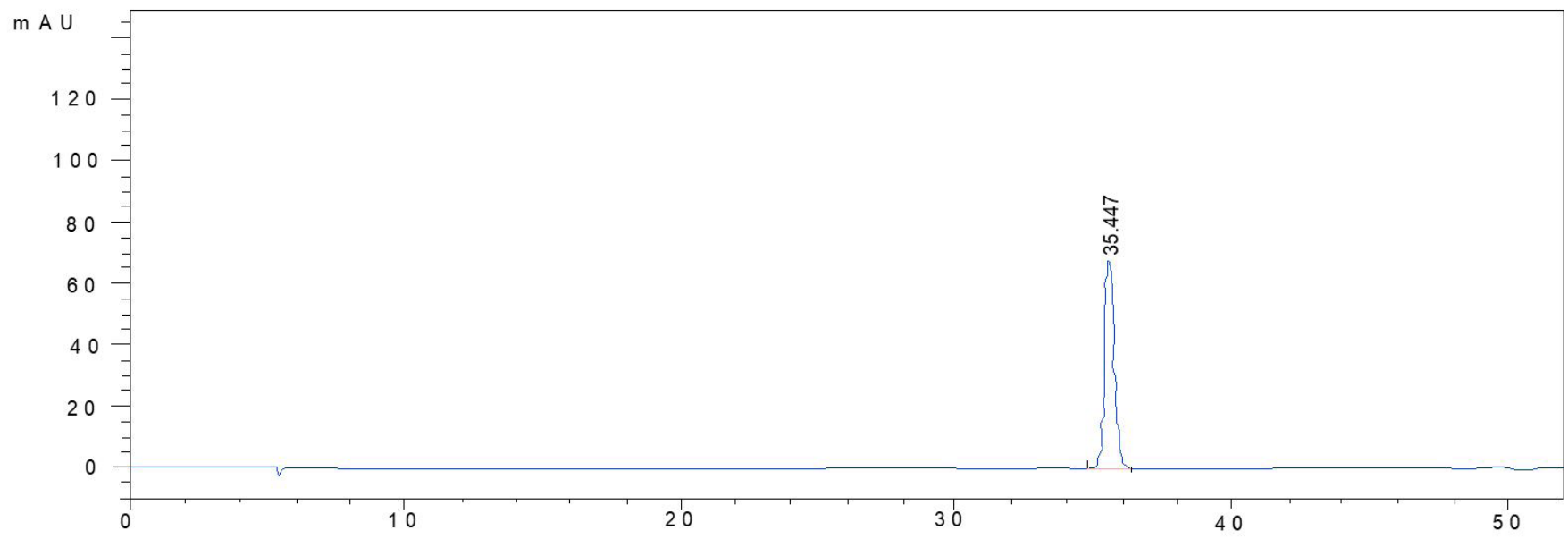

Figure 2. HPLC results of the CGE standard.

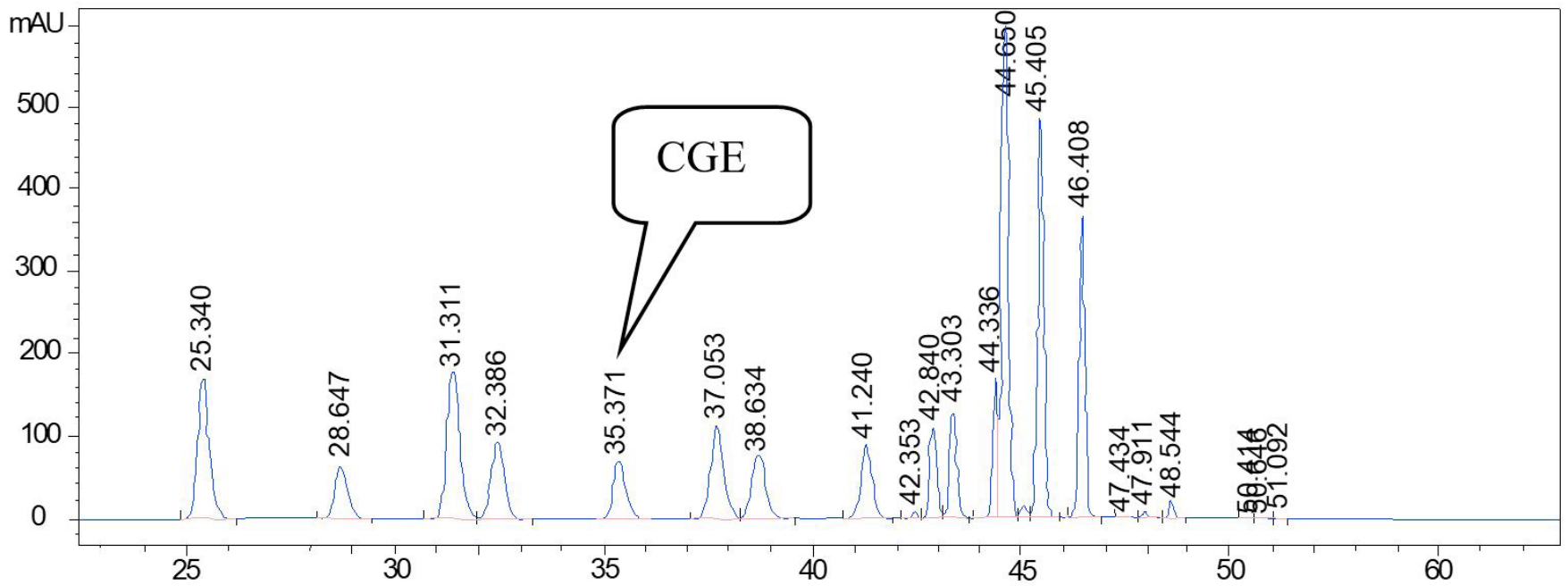

Figure 3. HPLC results of the sample.
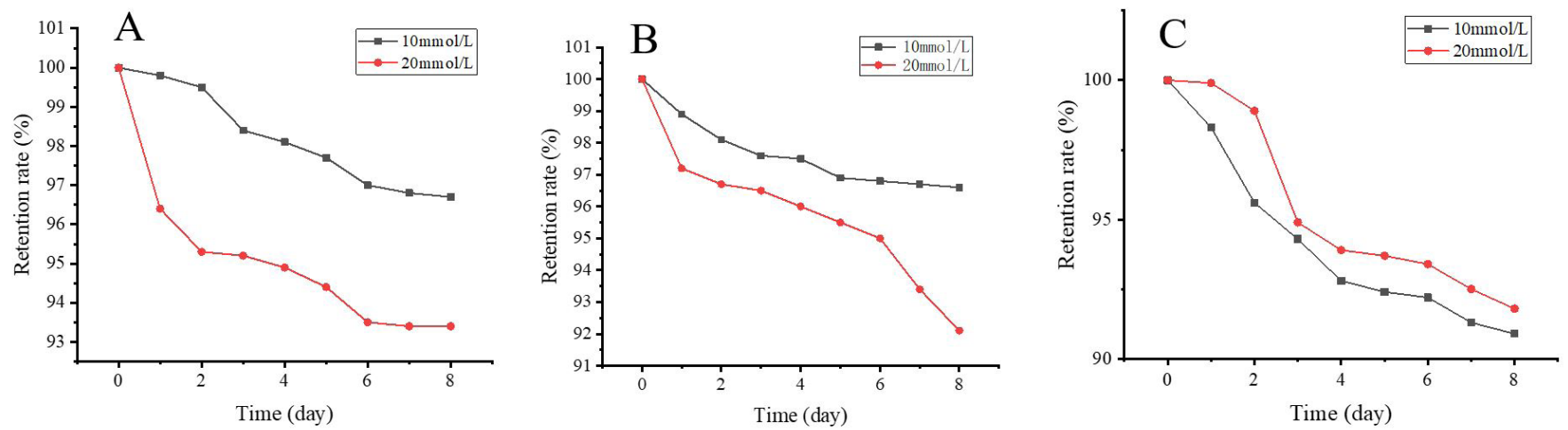

Figure 4. The influence of different concentrations of $\mathrm{K}^{+}(\mathrm{A}), \mathrm{Cu}^{2+}(\mathrm{B})$ and $\mathrm{Fe}^{2+}(\mathrm{C})$ on anthocyanin stability. 

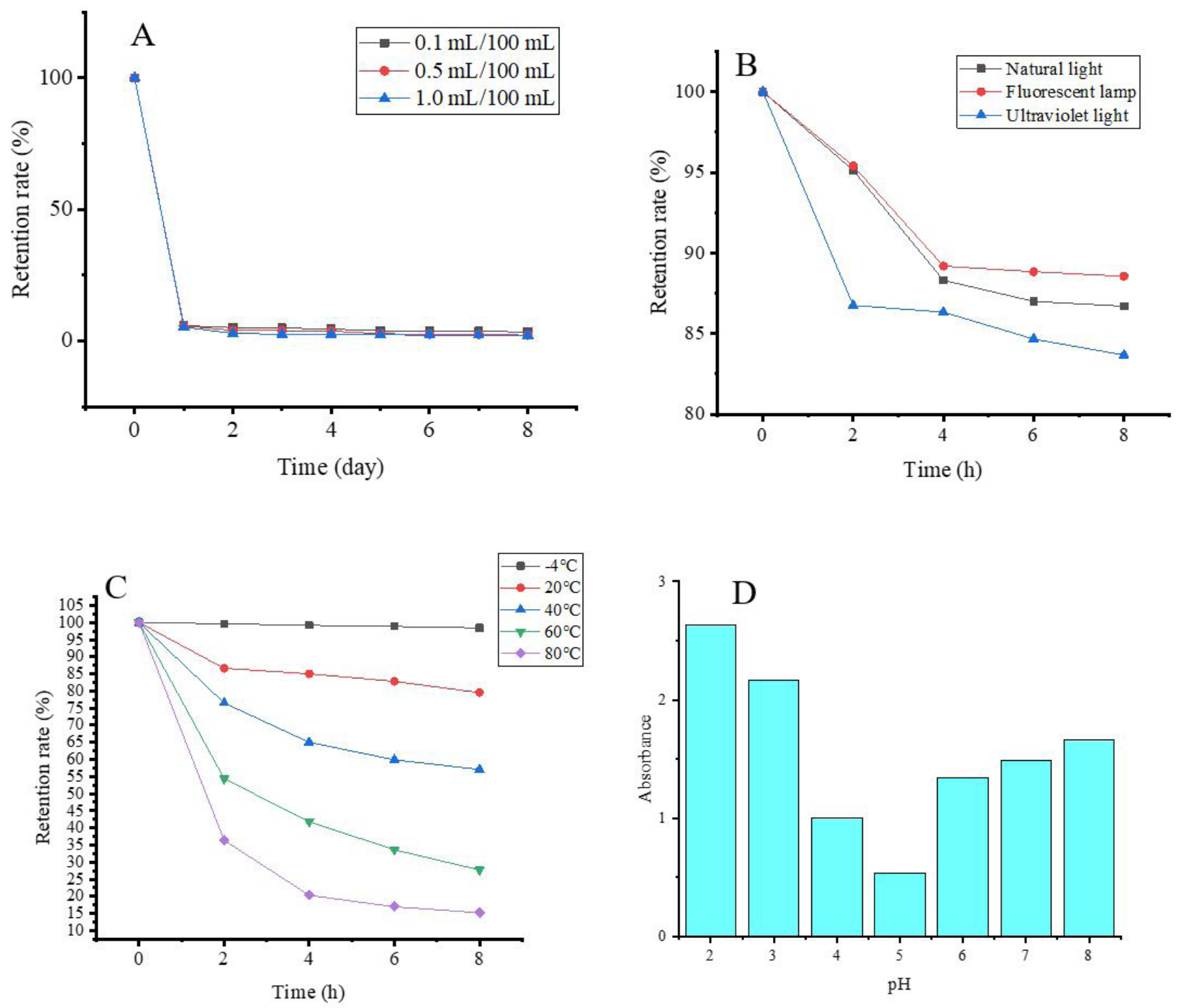

Figure 5. The influence of different volumes of $\mathrm{H}_{2} \mathrm{O}_{2}(\mathrm{~A})$, light conditions (B), temperature (C) and $\mathrm{pH}(\mathrm{D})$ on anthocyanin stability.

of extraction from rabbiteye blueberry fruits in Nanjing, the optimum conditions of the extraction were as follows: extraction time, $24 \mathrm{~h}$; extraction temperature, $30^{\circ} \mathrm{C}$; extraction solvent, $72.50 \%$ ethanol containing $0.02 \% \mathrm{v} / \mathrm{v}$ hydrochloric acid; liquid-to-solid ratio, 20:1 v/w; and extraction yield, $16.21 \pm 0.44 \mathrm{mg} / \mathrm{g}$. The extraction amount was high, but the extraction time was long, and the efficiency did not seem to be high.

The stability of anthocyanins is often affected by light, temperature, $\mathrm{pH}$, metal ions, oxygen and coexisting sugars (Riaz et al., 2012). The influence of temperature on the stability of anthocyanins is significant, and the increase in temperature leads to the thermal degradation of anthocyanins and the formation of brown products (Markakis, 2012). Light plays an important role in anthocyanin biosynthesis, but it also accelerates anthocyanin degradation. Amr \& Al-Tamimi (2007) confirmed that light has a very adverse effect on the stability of anthocyanins during storage. High oxygen contents can lead to a decrease in anthocyanin contents because anthocyanins inhibit radical activity at high oxygen concentrations, causing depletion of the antioxidant pigments (Gustavo et al.,2009). Anthocyanins are sensitive to changes in $\mathrm{pH}$. In this experiment, the color of blueberry anthocyanins changed with the change in $\mathrm{pH}$. When the $\mathrm{pH}$ was $2-5$, the solution turned red, and when the $\mathrm{pH}$ was $6-8$, the color turned dark brown. This indicated that anthocyanins could maintain their original color under acidic conditions but cannot exist stably under alkaline conditions. When a given anthocyanin is dissolved in water, the flavonoid cations form a series of secondary structures based on different acid-base, hydration, and tautomerism reactions (Chandrapala et al., 2012), changing their colors. 


\section{Conclusions}

In this study, the optimum extraction conditions of anthocyanins from organic Majiang blueberry from Guizhou were determined in terms of four parameters: solid-liquid ratio, ethanol volume fraction, ultrasonic extraction time and extraction temperature. The anthocyanin components were identified by HPLC, and the existence of CGE components was confirmed. The conditions of anthocyanin preservation were discussed, oxidationand temperature had the most serious influence on the stability of anthocyanins, followed by light and $\mathrm{pH}$. Metal ions had little influence on the stability of anthocyanins.

\section{Acknowledgements}

This work was supported by the first-class discipline construction project in Guizhou Province-Public Health and Preventive Medicine (NO. 2017[85]). Additionally, it was supported by Guizhou Provincial Natural Science Foundation (NO. LH 2016[7371]).

\section{References}

Amr, A., \& Al-Tamimi, E. (2007). Stability of the crude extracts of Ranunculus asiaticus anthocyanins and their use as food colorants. International Journal of Food Science \& Technology, 42(8), 985-991. http://dx.doi.org/10.1111/j.1365-2621.2006.01334.x.

Chandrapala, J., Oliver, C., Kentish, S., \& Ashokkumar, M. (2012). Ultrasonics in food processing: food quality assurance and food safety. Trends in Food Science \& Technology, 26(2), 88-98. http://dx.doi.org/10.1016/j.tifs.2012.01.010.

Chorfa, N., Savard, S., \& Belkacemi, K. (2016). An efficient method for high-purity anthocyanin isomers isolation from wild blueberries and their radical scavenging activity. Food Chemistry, 197(Pt B), 1226-1234. http://dx.doi.org/10.1016/j.foodchem.2015.11.076. PMid:26675861.

Diaconeasa, Z., Leopold, L., Rugină, D., Ayvaz, H., \& Socaciu, C. (2015). Antiproliferative and antioxidant properties of anthocyanin rich extracts from blueberry and blackcurrant juice. International Journal of Molecular Sciences, 16(2), 2352-2365. http://dx.doi.org/10.3390/ ijms16022352. PMid:25622252.

Duan, W. K., Jin, S. P., Zhao, G. F., \& Sun, P. L. (2015). Microwaveassisted extraction of anthocyanin from Chinese bayberry and its effects on anthocyanin stability. Food Science and Technology, 35(3), 524-530. http://dx.doi.org/10.1590/1678-457X.6731.

Giusti, M. M., \& Wrolstad, R. E. (2001). Characterization and measurement of anthocyanins by UV-visible spectroscopy. Current Protocols in Food Analytical Chemistry, 2(1), 19-31. http://dx.doi. org/10.1002/0471142913.faf0102s00.

Gustavo, A., González-Aguilar, J., Fernando Ayala-Zavala, F., Laura, A., de la Rosa, D. L., \& Alvarez-Parrilla, E. (2009). Phytochemical changes in the postharvest and minimal processing of fresh fruits and vegetables. In L. A. de la Rosa, E. Alvarez-Parrilla \& G. A. González-Aguilar (Eds.), Fruit and vegetable phytochemicals: chemistry, nutritional value, and stability (pp. 309-339). Ames: Wiley-Blackwell.

Hu, Y., Li, J., \& Hui, B. (2006). Study on major nutrition and anthocyanins of blueberry. Shipin Kexue, 27, 600-603.
Hutabarat, R. P., Xiao, Y. D., Wu, H., Wang, J., Li, D. J., \& Huang, W. Y. (2019). Identification of anthocyanins and optimization of their extraction from rabbiteye blueberry fruits in Nanjing. Journal of Food Quality, 2019, 6806790. http://dx.doi.org/10.1155/2019/6806790.

Lee, J., Rennaker, C., \& Wrolstad, R. E. (2008). Correlation of two anthocyanin quantification methods: HPLC and spectrophotometric methods. Food Chemistry, 110(3), 782-786. http://dx.doi.org/10.1016/j. foodchem.2008.03.010.

Lee, S. G., Vance, T. M., Nam, T. G., Kim, D. O., Koo, S. I., \& Chun, O. K. (2016). Evaluation of pH differential and HPLC methods expressed as cyanidin-3-glucoside equivalent for measuring the total anthocyanin contents of berries. Food Measure, 10(3), 562-568. http://dx.doi.org/10.1007/s11694-016-9337-9.

Markakis, P. (2012). Anthocyanins as food colors. New York: Elsevier.

Mikulic-Petkovsek, M., Slatnar, A., Stampar, F., \& Veberic, R. (2012). HPLC-MSn identification and quantification of flavonol glycosides in 28 wild and cultivated berry species. Food Chemistry, 135(4), 2138-2146. http://dx.doi.org/10.1016/j.foodchem.2012.06.115. PMid:22980782.

Riaz, M., Zia-Ul-Haq, M., \& Saad, B. (2012). Biosynthesis and stability of anthocyanins. In M. Riaz, M. Zia-Ul-Haq \& B. Saad (Eds.), Anthocyanins and human health: biomolecular and therapeutic aspects (pp. 71-86). Cham: Springer.

Silva, S., Costa, E. M., Calhau, C., Morais, R. M., \& Pintado, M. M. E. (2017). Production of a food grade blueberry extract richin anthocyanins: selection of solvents, extraction conditionsand purification method. Food Measure, 11, 1248-1253.

Thomasset, S., Teller, N., Cai, H., Marko, D., Berry, D. P., Steward, W. P., \& Gescher, A. J. (2009). Do anthocyanins and anthocyanidins, cancer chemopreventive pigments in the diet, merit development as potential drugs? Cancer Chemotherapy and Pharmacology, 64(1), 201-211. PMid:19294386.

Urias-Lugo, D. A., Heredia, J. B., Muy-Rangel, M. D., Valdez-Torres, J. B., Serna-Saldívar, S. O., \& Gutiérrez-Uribe, J. A. (2015). Anthocyanins and phenolic acids of hybrid and native blue maize (Zea mays L.) extracts and their antiproliferative activity in mammary (MCF7), liver (HepG2), colon (Caco2 and HT29) and prostate (PC3) cancer cells. Plant Foods for Human Nutrition, 70(2), 193-199. PMid:25762472.

Wang, J., Kalt, W., \& Sporns, P. (2000). Comparison between HPLC and MALDI-TOF MS Analysis of Anthocyanins in Highbush Blueberries. Journal of Agricultural and Food Chemistry, 48(8), 3330-3335. PMid:10956111.

Xu, Q., Zhou, Y. J., Wu, Y. X., Jia, Q., Gao, G. L., \& Nie, F. (2016). Enzymeassisted solvent extraction for extraction of blueberryanthocyanins and separation using resin adsorption combinedwith extraction technologies. International Journal of Food Science \& Technology, 51(12), 2567-2573. http://dx.doi.org/10.1111/ijfs.13240.

Xue, H. K., Xu, H., Wang, X. R., Shen, L. Y., Liu, H., Liu, C., Qin, Q. Y., Zheng, X. Z., \& Li, Q. Y. (2018). Effects of microwave power on extraction kinetic of anthocyanin from blueberry powder considering absorption ofmicrowave energy. Journal of Food Quality, 2018, 1-13. http://dx.doi.org/10.1155/2018/9680184.

Yildiz, E., Guldas, M., Ellergezen, P., Acar, A. G., \& Gurbuz, O. (2020). Obesity-associated Pathways of Anthocyanins. Food Science and Technology. In press. http://dx.doi.org/10.1590/fst.39119. 